\title{
Linguistic Principles of Naming Trade Objects in Uzbek Language
}

\author{
Durdona Lutfullaeva ${ }^{1}$, Ra'no Davlatova ${ }^{2}$, Salima Rustamiy ${ }^{3}$, Abdulazizkhan Nig'monov ${ }^{4}$ \\ ${ }^{1}$ Doctor of Philology, Professor, International Islamic Academy of Uzbekistan. E-mail: \\ isfan2006@mail.ru \\ ${ }^{2}$ Candidate of philological Sciences, Associate Professor, Navoi State Pedagogical Institute \\ Uzbekistan. \\ ${ }^{3}$ Doctor of Philology, Associate Professor, International Islamic Academy of Uzbekistan \\ ${ }^{4}$ International Islamic Academy of Uzbekistan
}

\begin{abstract}
This article provides information on the issue of naming in world marketing, naming technology various problems related to the linguistic aspect of naming technology, the specific norms of name formation in the Uzbek language. The sign of informativeness of the names of trading objects also indicates the original purpose of this object, what products it is intended to trade with. In creating a name, it is necessary to take into account the linguistic norms of a particular language, as well as people's culture, worldview, mentality, psychology, etc. The name created by it serves as a useful communicative communication function between the commercial object and the consumer, the name helps the commercial object to occupy a strong position in the market competition. From this point of view, the development of norms for naming specific objects of each language is one of the urgent tasks of today.
\end{abstract}

Keywords: naming, name, creation of names, naming technology, linguistic basis for creating names, brand names, product name.

Article Received: 10 August 2020, Revised: 25 October 2020, Accepted: 18 November 2020

\section{Introduction}

It is well known that, names, no matter what object they name, are the product of creation created by language owners. No matter what person, object, institution, or product is given a name, it is based on the re-perception of language speakers. While creating a name, a linguist uses his knowledge of the external world, sorts it out, analyses it; also uses a stock of lexical units and tries to create a name as it pleases.

Any name created by people is a product of human needs. Names are created based on the need to name a specific object, product, etc., and on this basis to distinguish and communicate with similar objects and products.

The name not only serves as a noun, but also acts as a bridge for communication between people. At this point, there is an "invisible" dialogue between the creator of the name and the person who understands it. The name of the product can provide information about the product or its manufacturers. Or the name of the institution provides information about the type of activity in which it is carried out. Hence, the name serves as both a carrier and a transmitter of information.

The names vary depending on what the object is named. In particular, the names describing the object of production, trade objects, enterprises, products or goods, their brand differs from other types of names in that it has features such as having a specific purpose, affecting the consumer, being able to interact with it. The activity of creating a name for such objects, manufactured products, is called naming in marketing. 
Based on Naming's dictionary, it is not just a choice of words (this can be only one stage of the activity), but also the creation of a unique system of languagecommunication, in which a brand consisting of a name interacts and language can be the subject of communication with the user.

In fact, the names given to trade objects (shops, markets, counters), first of all, should serve as giving a brief information about the main purpose and function of these objects, the original nature of the product, thereby providing primary communication with the consumer. In this process, the name also serves as an emotional expression.

It is well known that the names given to commercial objects differ from other types of names in that they perform several functions at the same time. First of all, such names are linguistic units that name objects of trade. However, the object of trade is a secondary name based on human psychological imagination. Such names also reflect the national perception of reality, the associative thinking of language owners. They not only name the object of sale, but also carry basic information about the purpose of the object. Names act as a bridge of communication between businesses and language owners (consumers). Names of this type also serve to emotionally influence and attract language owners (consumers).

It is clear that the creation of a name in naming linguistics requires a special activity, a creative process.

\section{Materials and Methods}

Working on the basis of techniques such as comparing existing names in consumption, analyzing, recommending new names will ensure the consistency of the study.

Each language has its own linguistic laws of name creation. Like any name, trade names also form an idea specific to the object of trade in the minds of consumers about the most important aspects. Such a combination of perceptions leads to the formation of the image of the object of trade in the human mind. Of course, this image of a particular object of trade is a semantic image enriched with national-cultural views, worldviews, perceptions, subjective attitudes.

While names reflect the language owners' perceptions of the commercial object and their national and cultural perspectives, their study in relation to the human factor that perceives it helps to identify the specific national aspects of the naming mechanism in each language.

It is not a secret that the success of the competition in the global market depends on the chosen name. A successfully chosen name can draw the consumer's attention to the object of sale. Since ancient times, people have used a variety of methods to create a name: in the main case, the trade object was given the name of the city, village, street where the object is located, or named after its founder. Sometimes the name of a trade object is given same to the names of people, often the names of celebrities, the names of the heroes of the work. For example: Farhod Farmer's Market, Kokcha Market, Chilanzar Bazaar, Chorsu Bazaar. The first name, as a precedent, is firmly rooted in the linguistic consciousness of the Uzbek people. The name is associated with the name of the hero of the epic "Farhod va Shirin", and next names are associated with the name of the ancient districts of Tashkent. Of course, the antiquity of these names and their place in the memory of language owners as a name associated with the object of trade allows to ensure the communicative connection of the name with the consumer. However, unless the names or place names of the people placed on the item are directly related to the item, they will not be able to provide the consumer with primary information about themselves. In our opinion, in such cases, the name can't establish a close relationship with the consumer.

Any name given to trade objects, in addition to performing a nominative function, must also have the following characteristics: 1) informativeness; 2) 
communicativeness; 3) the nature of the speech effect.

An informative feature of the names given to trade objects is their important aspect. Such names should provide primary information about the nature of the object or product being named. For example, a store name should provide general information about the main products (food, clothing, shoes, etc.) sold in the store.

The informative symbol of the names of trade objects also indicates the original purpose of the object, what products it is intended to trade with. For example, the purpose of the "CLEAN CLOTHES" store in Tashkent is to sell clothes. Or the name "SOMONBOZOR" indicates the sale of straw in the market. This indicates that the communicative purpose of the names is also hidden in the information label.

The communicative function of the names of trade objects is reflected in the relationship between the name of the object and the consumer. The consumer enters into an invisible communication with the object of trade in the process of obtaining information by name. That is, the name provides the consumer with information about the object of trade, and the consumer receives this information directly.

Sometimes the formation of various associations associated with a name in the mind of a person who has heard or read the name also indicates the formation of a communicative bridge between the name and the consumer. For instance, the name "SHARQ BOZORI" is reminiscent of our national products. This indicates that there is a connection between the name and the consumer.

The communicative function of names is determined on the basis of communicative effectiveness. Communicative effectiveness is when a name conveys certain information to a consumer and thus communicates with it.

The creation of a name in a language unknown to the speakers also creates a primary barrier to communication, that is, the transmission of information through the name and its reception by the consumer. It is known that in recent years it has become a tradition in our country to name production, trade facilities and products in foreign languages. Especially in the last three or four years, there has been a tendency to use English words when creating names. The naming of retail outlets, especially shops, in foreign languages that are incomprehensible to language owners, also hinders the establishment of primary communicative communication with the consumer through the name. Of course, every language has certain requirements and criteria for creating a name, and compliance with it is one of the conditions for the communicative effectiveness of the name.

Names are also important in terms of their ability to influence consumers verbally. Such names not only name a production, enterprise, trade object, or product, but also perform a pragmatic function in terms of attracting the consumer. In particular, the names of objects for commercial purposes should attract the consumer, first of all, by name. The name serves as a speech effect while attracting the consumer.

It is important to follow the lexical rules of the language, especially when naming commercial objects. The names chosen for trade objects in our country over the past years are lexically diverse. When we look at the lexical structure of the names used in practice, we see that in the creation of the name, along with Uzbek words, a mixture of foreign words was used. Such names can be divided into the following types:

1. Names formed with their own language units (or units that have become their own language units): Qo 'yliq dehqon bozori (Quyliq market), Mirobod dehqon bozori (Mirobod market).

2. Names formed with other language units: "Mesnoy market", "REDTAG", "Andalus" supermarket, "Elegance" store.

3. Names formed by own and other language units: "Sharq original 
mebel"(Sharq original furniture) store, Parkent specialized shopping centre.

It is not a secret that among them there are cases of naming with other language units, as well as with their own language units. Such names are created in English, Russian or with the participation of these language units and are widely used in business.

The lexical norm of the Uzbek language requires the name creator to use lexical units appropriately and purposefully. The use of foreign words in the name that is unfamiliar to the speakers of the language, or the fact that the word does not serve to give an idea of the object, enterprise, firm or purpose, indicates that it was not chosen correctly. Adherence to the lexical norm of the language in creating a name ensures the success of the name

Another requirement for creating a name is to follow the rules of word formation. When creating a name for a business, it is important that the wording conforms to the specifics of the language. Adherence to them serves to ensure the communicative effectiveness and efficiency of created names. When creating a name, first of all, it is advisable to use the internal capabilities of each language. It is possible to create a name in Uzbek using all methods of word formation. We must take full advantage of these features of our language when creating a name.

Violation of syntactic norms in the creation of names for trade objects prevents the names from being short, simple, clear and resonant. The name should be simple in order to attract the consumer. Long names are not remembered much by the consumer, they do not attract him. Such names cannot even be given in abbreviations.

Adherence to the orthographic norms of the Uzbek language in the creation of the name contributes to the correct perception of the name by the consumer. The name is the face of its creator, the name written with spelling mistakes creates negative emotions in the consumer. Names should not be used as a laughing stock for linguists.

Another requirement for the creation of a name is that the name should correspond to the national and cultural views, mentality attitude to reality of the members of society. Names that are alien to members of the community or that create negative associations in their thinking cannot form effective communicative communication. This means that the name must be linguistically perfect, but it must not even have a negative effect on the human psyche, it must be in line with the national-cultural views of the speakers, the national moral norms.

\section{Results}

Studying the experience of creating a name in the Uzbek language, we believe that the following strict criteria should be followed when naming a trade object:

1. The name reflects the most important information about the object of trade.

2. Adherence to the literary norms of the language (phonetic, lexical, orthoepic, grammatical, methodological norms) in the creation of the name.

3. The name does not contradict the national cultural views, traditions, mentality, worldview, psychology of language speakers.

4. The name does not contradict the principles of the socio-political system.

5. The name does not evoke a false image in a person, but rather attracts him, creates a positive attitude in his imagination, as well as, it is quickly and easily remembered.

6. The name should be clear, concise and easy to pronounce for native speakers.

7. The name serves for effective communicative communication.

8. The name acts as a bridge between the product and the consumer.

9. The name should not be the same as other names they should not remember the products they mean. 
It is understood that names must also meet phonetic, orthoepic, and grammatical language norms. The easy pronunciation of names indicates that they are strictly in accordance with phonetic and orthoepic norms. Names are difficult to pronounce can confuse the consumer and quickly fade from his memory. Even when the names are too long could bring difficulty to the speaker it is not easy for him to quickly remember the names of the long sentences. The fact that the names are short, clear, and easy to remember shows that they were chosen successfully.

Name creation technology also has certain requirements for the name creator. In particular, a perfect knowledge of the norms of literary language from the creator of the name, the ability to accurately and truthfully assess the impact of language, the ability to use language units in the creation of the name in an appropriate and appropriate manner, importantly, the created name requires the ability to create effective communicative communication between producer and consumer, commercial product and buyer. This means that the name cannot be created by any language owner, and that certain rules must be followed when creating a name.

\section{Conclusion}

So, in addition to the linguistic norms of a particular language, it is necessary to take into account the culture, worldview, mentality, psychology of the people. The name created in this way serves as a beneficial communicative link between the trade object and the consumer, the name helps the trade object to take a strong position in the market competition.

\section{References}

[1] Kazanskaya L.P. Linguistic problems of naming. Linguistica Bidgostiana. Bydgoszcz. 2012. - p.92.

[2] Sasina S.A., Bricheva M.M. Linguistic aspects of naming (based on English-speaking brands) // "Bulletin of
ASU”, vol. 2 (197). 2017. -p. 114.

[3] Pankrukhina A.P. Marketing: a large explanatory dictionary. Moscow: Omega L., 2011. -p. 1.

[4] Lutfullaeva D., Davlatova R., Tojiboev B. Associative Dictionary of the Uzbek Language.Tashkent: "NAVOIY UNIVERSITETI”. 2019.

[5] Lutfullaeva, D. (2008). Pragmatic features of Uzbek verbs. The role of women scientists in the development of science and technology (Materials of the Republican scientific-practical conference). Tashkent: TDPU.

[6] Rustamiy, S. (2019). ON SIGNIFICANCE OF SCIENCE OF BALĀĞAT IN ACHIEVING LINGUISTICAESTHETIC PERFECTION. The Islam, 2019(4), 14.

$$
\text { Light of }
$$

[7] Sayidirahimova, N.S. (2020) Semantic classification of the syntax antonyms of uzbek language. International Scientific Journal.Theoretical \& Applied Sciencею. Philadelphia, USA, 2020. P. 671-673.

[8] Arifdjanov, Z. (2020). Functional خواستن equivalents of the simple verb [xāstan] and their formal invariants. The Light of Islam, 2020(1), 163-170.

[9] Nasirova, M. A. (2019). THE CONTRIBUTION OF THE OUTSTANDING MAVARANNAHRIAN SCHOLAR MAHMUD AZZAMAKHSHARI INTO THE WORLD LINGUISTICS. International Scientific Journal. Theoretical and Applied Science. Clarivate Analytics. Philadelphia, USA 2019.(10), 755-759.

[10] Nig'monov Mr, A. (2020). RHYTHMIC-SYNTACTIC

PARALLELISMS IN OLD TURKIC POETRY (BY EXAMPLE OF EXTRACT FROM "DEVON LUGATI-TTURK"). The Light of Islam, 2020(1), 185191.

[11] Davlatova R.Kh. Pragmatic analysis of the linguistic concept of personreferencing deixis and pronouns referring to 
it in the uzbek language. Journal of Critical Reviews / ISSN- 2394-5125 Vol 7, Issue 5, 2020. 350-354-p. http://dx.doi.org/10.31838/jcr.07.05.68

[12] Davlatova R.H. Social condition deixis and its expression in uzbek language. ACADEMICIA: An International Multidisciplinary Research Journal. 2020, Volume: 10, Issue: 4. 259-265 p.

[13] Esonovna, L. D., Anvarovna, N. M., Sayidmahamadovna, S. N., Alimullaevna, N. F., \& Kakhramanovna, S. N. (2020). PRAGMATIC FEATURES OF OFFICIAL TEXTS AND DOCUMENTS OF THE UZBEK LANGUAGE. ANGLISTICUM. Journal of the Association-Institute for English Language and American Studies, 9(7), 27-34. $\begin{array}{lrr}\text { [14] Islomov, Z. (2019). } & \text { SOURCE } \\ \text { STUDIES } & \text { ANALYSIS } & \text { OF }\end{array}$
MANUSCRIPTS OF "MUQADDIMATULADAB" IN FOREIGN ARCHIVAL FUNDS. The Light of Islam, 2019(4), 41.

[15] Rustamiy, S. (2016). "Esasu-1belaga" ve "Divan-u lugat-it-türk" eserlerinin dil bilimi ve belagat bilimiyle ilgili yönleri. Electronic Turkish Studies, 11(20)

[16] Shoaliyeva, N. (2019) "SEVEN STAGES IN "MANTIC UT-TYRE" ("THE JOURNEY OF LOGIC") BY ATTAR IN SUKHROB SIPEHRI'S POEM "ADRESS"," The Light of Islam: Vol. 2019 : Iss. 4 , Article 19. Available at: https://uzjournals.edu.uz/iiau/vol2019/iss4/ $\underline{19}$

[17] Nizamova, Feruza (2019). The history of studying Khusrav Dekhlavi's work. The light of Islam, 2019 (2), 19. 9599 